\title{
Gender and Language Education Research: A Review
}

\author{
Abolaji S. Mustapha \\ Sheffield Hallam University, United Kingdom; \\ Lagos State University, Nigeria
}

\begin{abstract}
Gender and language education studies have multiplied in the past one decade. However, it does not appear that any state-of-the-art article has reviewed the various undertakings. This paper attempts to fill this gap by focusing on gender representation in learning materials and classroom interaction studies globally within gender and education literature. Selected studies from the 70 s to date are reviewed under three phases and suggestions for further investigation are made with the anticipation that learning materials and classroom interaction studies would help facilitate the achievement of the goal of gender equality in and through education.
\end{abstract}

Index Terms - language education, gender, research, review

\section{INTRODUCTION}

Since Holmes's (1991) and Sunderland's (2000) state of the art artic les on gender and language studies, it appears that no similar undertaking (nor a follow-up article) has been published till date, at least to cover the gap. In this present review, I plan to fill this gap by focusing on a narrower area of gender and language education studies, that is, gender in learning materials and classroom interactions research.

Holmes and Sunderland among others provide state of the art articles on gender and language studies up to the latter part of twentieth century. While Holmes (1991) provides a broad view of gender and language studies, Sunderland's dwells on specific areas and reviews studies within the wider area that Holmes (1991) addresses. Thus while Holmes dwells on language and gender and lists many references, Sunderland (2000), starting from the previous works, narro ws her review to language and gender in second and foreign language education highlighting on areas such as - gender and language learning; gender, language learning and ability,; second/foreign language acquisition and the four skills; motivation/investment; language learning styles and strategies; classroom interaction; the 'what' of teaching: English as a non-sexist language?; teaching materials; language testing; teachers, professional organisations and gender, what can teachers do? teacher action and teacher education; new theorisations of language and gender; language learners' identities; masculinities: boys, men and language learning; and future research.

Interestingly, one of the areas that Sunderland reviews in her article - gender and education has attracted so many studies that any exhaustive review of studies in the area might yield volu mes and might triple what Sunderland (2000) did. Thus, in this present review, I shall focus on gender representation in learning materials and classroom interactions across languages which parallel Sunderland's (2000) "the what of teaching: English as a non-sexist language".

Sunderland's (2000) state of the art article particularly addresses gender and language education covering large areas (though she notes that it is not comprehensive comparing what had been done in the area with the coverage of her article). However, it might be near impossible to attempt another of its kind today after a decade since the review was published in Language Education in 2000. Yet as Sunderland rightly observes, her review is quite selective and restrictive to second and foreign language education although in passing she lists some works on first languages (e.g. German, French, and Spanish). In this present review, I shall extend my coverage to include studies in first languages such as German, French among others. Thus my review covers some first languages but shall be restricted to one area out of the many areas that Sunderland (2000) addresses and shall include studies from the 70s to the present.

Although there are studies in the social sciences that have addressed gender in education, I shall concern myself with those that are domiciled in language studies. This restriction is necessary because of the fast growing number of research being done on the subject matter in response to recurrent calls from and funding by government agencies, international organisations (UN, World Bank, Commonwealth of Nations among others) and other non-governmental organisations.

\section{BACKGROUND}

Studies in this area (with in gender difference and identity paradigms) have multiplied and are still growing for a number of reasons. One of the reasons is that government bodies in Europe, A merica, and Asia and in some developing countries including some international organisations have picked interest in the area. This interest is in response to United Nations declarations under its hu man rights programmes that are geared towards bringing about gender equality 
in and through education for males and females...not only in terms of parity (gender-balance in enrolment) but also in the quality of education on offer for boys and girls. In fact, UN, Common wealth of Nations, Ford Foundation among others have called for and sponsored research undertakings in the area. For example, the Ford Foundation funded the research project into gender representation in textbooks used for learners in China and also funded the follow-up actions that saw the publications of gender-fair textbooks for its education sector (Ross and Shi, 2003; Zhang, 2003; Zhao, 2002).

Another reason is closely associated with the activities of the feminist movement. According to Cameron (1998), research in this area was sparked off by feminist movement in the 1960s when what they might contribute in linguistic sphere dawned on its members. Feminist researchers' demand for a combination of reflection and practice that they refer to as 'praxis' Freire (1970) and a need for experts in various areas of language teaching to expose and transform social injustice through research and pedagogical practices within classroom, schools, communities, and society at large (Davis and Skilton-Sylvester, 2004, p. 398 cited in Mukundan and Nimehchisalem, 2008, p. 156) were welcomed and taken up with attendant studies that abound in the literature.

It might be added that the responses that have attended the findings of many of these studies (as follow-up activities) in Europe, America and some parts of Asia such as the reformation of gender-biased texts, the production of guidelines and plan of actions, the co-operation of authors and publishers that followed guidelines that ensure gender-fairness in textbooks also encouraged further studies in under-researched sites. Gender fairness in learning materials advocates for equal treatment and opportunities, and representation of both sexes. It discountenances every form of genderstereotypes, discrimination against any sex group in any form of invisibility and domination by the other sex group. It seeks to present both female and male characters as complementary members of society each capable of making mean ingful contributions towards local and national development.

One common denominator in all these studies is the belief that learning materials are laden with gender-biasness, a feature that is inimical to the achievement of gender equality in human society. At the centre of these undertakings are the arguments about and discontent with the ways the sexes (females and males) are represented which are rather imbalanced or unfair especially to wo men. And the kind of biased representation reported in the literature might directly or indirectly shape gender identities that will not augur well with the educational goals of our contemporary society, especially the need for gender equality in qualitative education and empowerment of women for social, economic and national development. In addition, teachers' role (their talk around the text) in the classroom has been brought under scrutiny as their part in entrenching the dominant culture (gender unfairness) of society also contributes towards gender inequality.

However, it appears that 'text' studies has occupied the centre stage as there are more 'te xt' studies than 'talk' studies, the latter being a follow-up of the former. The important role that school activities and materials play in socializing learners is underlined in Holmes's (2009, p. 3) observation that "social institutions such as family, school, the workplace and the media teach us that girls should act in certain ways, such as being caring and boys in different ways, such as being strong and independent".

\section{THE IMPORTANCE/ROLES OF TEXTBOOKS}

The place of textbooks in socializing learners cannot be overemphasized, especially as textbooks are often vie wed by learners as authoritative, and there fore have the potential to influence a significantly large and impressionable audience (Foshay, 1990; Robson, 2001). In addition, textbooks serve as a "means to facilitate the integration of content about ethnically, racially and culturally diverse populations" (Sileo and Prater, 1998, p. 05). To Mustedanagic (2010), whenever a text is read, an interpretation is made by the reader and meaning is constructed. Comparing language teaching with build ing a house, she says that "the text represents our material ... therefore, bad material, bad building".

Stressing the place of textbooks, Mukundan and Nimehchisalem (2008) noted that the textbooks...young people focus on repeatedly during the classroom practice, follow-up assignments or projects, and preparation for examination exert influence on the learner in terms of the quality of education they receive, their understanding of social equality and national unity. Putting it very strongly, both Poulou (1997) and Treichler and Frank (1989) reported that linguistic sexis $m$ in textbooks creates deleterious real-world and damag ing pedagogical consequences especially for women and girls.

The role that textbooks play in educating learners has attracted the attention of other scholars. For example, Stromquist, Lee and Brock-Utne (1998) noted that

educational institutions are powerful ideological institutions that transmit dominant values, and function as mechanis ms of social control...schools transmit values that not only reproduce social class but also main gender structures...the formal school system contributes to the reproduction of gender inequalities through such mechanis ms as selective access to schooling, the content of what is being taught and what is not and how it is taught and the kinds of knowledge men and wo men (and boys and girls) get (p. 83).

Their paper drew attention to what goes on in the educational system/process and how this impacts on the learner. Stromquist, Lee and Brock-Utne (1998) claim that the formal curriculum covers the knowledge and skills school officially seeks to transmit via their program of studies, courses and textbooks. To them, not many studies have explored the effects textbooks have on learners; consequently they call for longitudinal research tracing influences over 
time. They conclude that observers and educators acknowledge that textbooks and curricular content leave lasting influences in our memories, as phrases and stories heard, read and written about men and women condition our minds (Stro mquist, et al.. 1998, p. 83-97).

\section{THE HIDDEN CURRICULUM}

These observations opened up what had hitherto been hidden to many researchers. Thus studies that gave serious attention to the influence of textbooks on learners suggest that such influences are subtle... thus the term 'hidden curriculum'. Talking about hidden curriculum, Stromquit et al. (1998, p. 398) noted that the informal curriculum, popularly called hidden curriculu $\mathrm{m}$ is the set of knowledge that is transmitted through the roles men and women play in the staffing of schools, the way teachers treat male and female students, and the manner in which adults interact with others. Some scholars have added another dimension to the hidden curriculum, which is the expectations teachers have of boys and girls regarding occupational and family roles, the differential vocational advice given to boys and girls, the behavioural norms and disciplinary sanctions enforced at school, and the re-creation within the school of norms and values concerning masculinity and femin inity by the peer group. Stromquit, et al (1998, p. 401) further distinguished between two kinds of curriculum from feminist perspective - non-sexist curriculum - one that is free of gender stereotypes and other forms of distortions and an antisexist curriculum - one that seeks to destroy stereotypes and to build a new way of perceiving and establishing social relations between men and women.

Zeroing in on textbooks, Stromquit et al. (1998) affirmed that textbooks are significant mechanis $m$ for the transmission of the informal curriculum. In addition to certain subjects, knowledge, and skills, books disseminate sexual bias, prejudice, and discrimination through the ways in which men and women are depicted in stories and from illustrations. By focusing on some and ignoring others, the identity of persons may be strengthened or weakened accordingly. Responses to these observations resulted in serious attention being directed at how textbooks help to foster imbalance gender education in the formal setting of learning.

Setting the agenda, a group of scholars set the goal, which was to produce gender-balanced curriculu m/textbooks (which requires collaborated effort and co-operation) that will alter the contents of the present gender-biased curriculum/textbooks so that males and females can see each other as sources of help and support, share their learning experiences, and learn to be responsible for one another's learning.

Working towards gender equality in education should not only focus on equal access to or provision of education to males and females (gender parity), the content of schooling should be given attention. Improving on school enrolment among boys and girls should be pursued especially in developing countries where enrolment gap between boys and girls has been very wide. However, considering the way "school narratives are constructed in basic terms that contrast and oppose masculinity and femin inity" particularly "the oppression of women by men should not be seen as a nonissue" rather they are crucial issues that demand urgent attention. Therefore, because "the formal curriculum, through textbook content and instructional dynamics, continues to promote the creation of gendered identities of asymmetrical nature... textbooks should continue to be a prime target in strategies to modify the curriculum (Stro mquit et al., 1998, p. 405).

For Renner (1997), it is important to eliminate sexis $m$ in the language use in order to provide an environment where every pupil can learn on equal terms. Essentially, the need to change the structure that supports sexis m in language use became important. Stressing the need to reform and gain thereby, Mills (1995, p. 95) mentioned that a gender-free language contributes to the acceptance of each human being, with out dominance from one group. Similarly, Stromquit et al. (1998, p. 405) note that the creation of a new social identity by means of school interventions necessitates the recognition of the value of endogenous culture, but it also requires the courage to discard traditional elements that are conducive to the oppression of wo men, whether in the name of culture or religion.

It is noted that prior to these discussions many studies have been done beginning from 1946. One of the earliest studies on record known to the writer was carried out by Child, Potter and Levine (1960) which discovered that primary textbooks are often portrayed rather negatively and stereotypically e.g., manipulative. According to Blu mberg (2007), with the advent of second wave wo men movement, studies multiplied and in 1971, activist Marjorie U'Ren published a content analysis of the 'The image of woman in textbooks' in an iconic feminist reader where she analyzed 30 of the newest textbooks adopted or recommended for use in second to sixth grade California schools. However, these discussions prompted increased interest in empirical studies of gender representations in textbooks in order to draw attention to gender imbalance and call for reform in the discriminatory representation of men and women in textbooks, reforms that will bring about equality or gender fairness - a way of engendering equality not only in the way we view both sexes but also in the way they are treated or given opportunities in human society. In what follows, we shall review three phases of research works that have been done together with methodological issues that have arisen before we suggest areas for further research and improvements.

\section{PHASES OF RESEARCH}

In this paper, I have identified three phases of studies for review - first phase studies that create awareness of gender imbalance in learning materials; second phase studies that served as follow-up studies by assessing responses and 
reforms in learning materials and the third phase - studies that extend the focus beyond textbook representations to talks around the text in classroom.

\section{A. First Phase Studies}

The need to reform language use and consequently change people's view about men and women moved gender and language researchers (especially feminists) to consider not just gender differences in language use (in day - to-day interactions) but also in language use in textbooks which is thought of as a form of social practice that is used by patriarchal society to entrench (as a way of gendering learners into stereotype masculin ity and feminin ity) gender parity and inequality to the detriment of women in society.

Consequently in the 1960s, 1970s and 1980s (Cincotta, 1978; Hellinger, 1980; U'ren, 1971) many studies were carried out and their findings indicate that texts, especially language textbooks were biased against femin inity. Males were portrayed in the bright of importance in occupations, public/social life, and decision makers in companies, corporations and government bodies. On the other hand, wo men were rendered invisible, or at lowest representation far less than men. For example, Cincotta (1978) revealed that both males and females perform gender stereotypical activities; Hartman and Judd (1978) showed that men were made more visible than women; women on the other hand tend to be stereotypically emotional and are more likely than male characters to be the butt of jokes. Hellinger (1980) found that males are over-represented while Porecca (1984) reported that men tend to occupy both more powerful and a greater range of occupational roles than women. There are other studies that reported similar findings.

From the studies carried out thus far in Jamaican, Malaysia, Greece, Spain and other places (Bailey \& Parkes, 1995; Cerezal, 1991; Chandran and Abdullah, 2003; Kanemaru, 1998; Mukundan, 2003; Poulou 1997; Seng, 2003; Talansky, 1986; Whiteley, 1996) gender imbalance in textbooks includes invisibility (fewer males than females or vice versa), occupational stereotyping (females in fewer and more menial occupational roles); relationship stereotyping (women are more in relation with men than men with wo men); personal characteristic stereotyping (wo men as emotional and timid); disempowering discourse roles (more males talking first and dominating roles in interactions) degradation (blatant sexis $m$ to the point of misogyny) (Sunderland, 1994, p. 55-56). So me other areas of gender imbalance in language have been highlighted from femin ist perspective. For example, Mills (1995) noted that phallocentrism prevai ls in gender and literature since generic sexism usage in language at the morphological, phrasal and sentential levels abounds e.g., affixes in occupational terms and generic pronouns in literature betray the lack of fairness to womenfolk.

Subsequently, as follow-up actions on the findings of many studies at this phase, guidelines for effecting corrective recommendations were produced. For example, McCormick's (1994) guidelines which were intended for stakeholders in the teaching sphere offer what Mustedanagic (2010) calls theoretical and practical guidelines for implementing a non-sexist classroom environment. UNESCO produced guidelines for text authors and publishers. Mills (1995) also provided guidelines for gender-free language. Government bodies and their education sectors were tasked with ensuring that gender balance in the process of curriculum development, text production and teaching/learning activities for educating the child. For example in Sweden, the country's LPO 94 under the Swed ish National A gency for Education stipulates that "The school should promote an understanding for others and the ability to empathize. Activities should be characterised by care of the individual's well-being and development. No one should be subject to discrimination at school based on gender, ethnic belonging, religion or other belief, sexual orientation or disability, or subject to other degrading treatment" (cited in Mustedanagic, 2008, p. 3). It appears that most of the first phase studies are largely content-based (analysis of the linguistic and non-linguistic representations in the textbooks) that did not address subjects of interactions between teachers and learners in the classroom.

\section{B. Second Phase Research}

Interestingly findings and recommendations from studies in the United States and Europe (where the studies kicked off) and in some parts of Asia yielded some desirable results although there are areas that are yet to be addressed or rather thinly investigated. For example, Sunderland (1994b) (pedagogical and other filters) reported changes in some of the textbooks she examined in Britain where newer grammar books from 1988 upwards encourage readers towards the avoidance of gender-specific language.

According to Blumerg (2007) by 1990s various second generation studies began to analyze the persistent (or not) of gender bias in a variety of substantive fields. Most showed modest improvements (sometimes very modest) handling texts at the high school, children's illustrated books and teacher training textbooks. For example, Zittleman and Sadker (2002) followed up Sadker and Sadker's (1980) study of gender bias in teacher training materials. The re -study, according to Blumerg (2007) involved 23 textbooks published from 1998-2001. Using the 1980 study evaluation methods, they found progress to be 'minimal' and disappointing. But despite the quantitative data showing that textbooks are far from gender-equitable, they also found that 'today's' textbooks are less offensive than those published more than 20 years ago.

Similarly, Mu kundan and Nimehchisale m's (2008) is a follow-up on earlier studies by Seng (2003) and Chandran and Adbudllah (2003) in Malaysia while Healy (2009) is a follow-up on studies done in the 1960s, 1970s and 1980s (Byrd, 2001; Hartman and Judd, 1978; Jones et al., 1997; Porecca, 1984). These studies fall within what we have categorized as second phase studies. They assessed progress made in ensuring gender balance in textbooks and further suggested areas that have not been covered by authors/publishers. For example, Healy (2009) reported that in the textbook that she 
examined the authors have managed to represent both sexes fairly evenly in the amount of talk - thus avoiding gender bias. Similarly, Sano, Iida and Hardy (2001) notes that although recent moves toward gender equality might have changed lexical choices made in Japanese EFL jun ior high school textbooks, and might have prompted the exclusion of explicit representations of stereotypical as sumptions from previous editions, regarding gender roles, however, implicit and metalinguistic messages in the existing texts suggest the need for a thorough analysis to evaluate the balance of gender representation. Their study reported that: "obviously, gender-imbalanced language has been substantially eliminated from EFL textbooks since 1990. There are no occurrences of gender-biased language such as chairman.... (however)...reading through the texts reveals prominence in the number of features focusing on male characters" (Sano, Iida \& Hardy 2001, p. 903-904).

Sweden and China appear to have achieved a higher measure of success. Blumerg (2007) noted that the initiative in China (funded by the Ford Foundation resulted in the development of 49 sets of non-biased primary and secondary school teaching materials, covering 20 subjects). The overall findings, according to Blumerg (2007, p. 22) showed that China's road to eliminate gender bias in textbooks and curricula will not be a short one, despite an official state of policy of achieving gender equity in education. (see Hui, 2003; Ross and Shi, 2003; Yi, 2002; Yi, 2003; Zhang, 2002; Zhang, 2003; Zhao, 2002). Similar success has been reported in Latin A merica (see Drayton, 1997; Go zalez, 1990).

In addition, it has been reported that the Nordic countries have been success ful in decreasing male stereotypes and improving male parenting skills through various school interventions (see, Carlson, 2007; SIDA, 2007) These studies led to the production of what has been described as 'progressive texts' although two major questions have been asked for which satisfactory answers are yet to be provided. The questions are whether gender representations in texts should reflect the goings in their contemporary society or the desired/expected gender balanced society that is far from what learners experience in their day-to-day life. The production of progressive texts that was reported in the West and in some parts of Asia, however, has not been reported in many parts of Africa, since pioneering studies (that would create awareness) are yet to be carried out. However, the shortcomings of the use of progressive texts were soon highlighted and taken up in subsequent research that characterise the third phase studies.

\section{Third Phase Studies}

Following the success recorded from studies on representations of gender in textbooks in Europe, A merica and some parts of Asia, researchers' attention has been drawn to some of the limitations of reformed or progressive textbooks. It has been argued that gender-balanced textbooks might still be turned around in the classroom by teachers or rather opposed by sexist female and male teachers who see themselves as agents of patriarchal society. These teachers tend to perpetrate the dominant culture they are used to thereby rendering reformed texts ineffective so that rather than reinforce the system of progressive texts they inhibit them.

Thus, Sunderland (2000) raised a germane question that suggested that research on gender representations in textbooks should not mark the end of the road. She did ask whether gender bias in textbooks does matter. In her answer, Sunderland (2000) observed that "it may not matter as much as these studies assumed - not because gender bias is unimportant (it will always matter to those who have principled objections to sexism in any shape or form), but because to focus on gender bias in a text may be to miss the point as far as learners and learning are concerned" (p. 153). She went further to buttress this position with the claim that:

...we cannot predict what a teacher will do fro ma text itself. A focus on gendered text alone, which assumes teacher treatment of the text is somehow evident from the text, would thus seem misguided. A text is arguably as good or as bad as the treatment it receives from the teacher who is using it; in particular, a text riddled with gender bias can be rescued and that bias put to good effect, pedagogic and otherwise (Sunderland, 2000, p. 155).

Sunderland's (2000) position, to us, rather than discredits what has been done on texts, pointed the way forward in gender and language education research. And that way forward is often tagged 'teacher talk around the text'. That means studies in some countries (excluding under-researched sites) should focus on how teachers use texts in learning environment. Sunderland (2000) observed that empirical studies are needed for teachers' use of texts. This new area is important for achieving the balanced or quality education that is at the centre of the whole efforts of gender equality. The focus on the teacher - what they do with texts in the classroom is important judging from what has been reported in the literature. For example, Bonkowski (cited in Alderson, 1997, p. 12) reported that language teachers often distort textbook authors' intentions, interpreting those intentions through their own models of language, language learning and language teaching. Similarly Shattuck (1996) (cited Sunderland, 2000, p. 155) also found that at a British Council School in Portugal, the teacher chose not to stick to the text but went beyond it, contributing observations of his own about the topic of discussion. Therefore teachers' treatment of gendered te xts and learners' interpretations or handling of gendered texts should be researched.

Although this new area has been taken up by a number of researchers but it has been noted that gender and language learning in classrooms has under-researched sites in developing countries in Africa, Islamic countries, Eastern Europe, South America, and China (Sunderland, 2000). Interestingly, in the past decade, some studies have emerged from some of these under-researched sites (Ansary and Babaii, 2003; Birjandi and Anabi, 2006; Gharbavi and Mousavi, 2012; Hamdan, 2010; Jafri, 1993; Khurshid, Gillani \& Hashmi, 2010; Lee and Collins, 2008; Lee, 2007; Madu and Kasanga, 2005; Sabir, 2008; Zhang, 2003; Zhao, 2003). 
Thus, research activities in the third phase studies indicate advancement and budding scholarship in the area especially in Europe. Concern with talks around the text is expected to complement the use of progressive texts in order to avoid loopholes in achieving elimination of every form of discrimination against any sex group either in text or in talk. However, it appears that while we look forward to seeing more studies on talk in some parts of Asia where progressive texts have been produced en masse, it does not appear that textbook research has attracted scholars' attention in Africa (barring South Africa and some parts of East Africa).

With the volume of studies on gender and learning materials and the largely common findings from the various studies across Europe, America, Asia and Latin A merica, one would anticipate a proposal for universals in gender and language education although more studies are still needed from Africa. Any proposal for universals, (barring the dearth of studies in some parts of Africa) might be hampered not only by the dearth of studies in Africa but also by the consideration that heterogeneity characterise the modes of data collection and analysis most of the studies do ne thus far are far. Thus the subject of methodology has attracted the attention of some scholars (Brugeilles and Cro mer, 2009; Lee, 2011)

\section{ISSUES OF METHODOLOGY}

One aspect of gender representations in textbook studies that has been very thorny has to do with methods of data collection and analysis. The argument surrounds heterogeneity of methods (content analysis, linguistic analysis, narrative approach, systemic functional approach, computer concordancing, collocation, transitivity, $d$ iscourse analysis, critical discourse analysis, role analysis, critical image analysis, elicitation method task method among others. Some scholars have argued that this is quite unwholesome. For example, Lee (2011) noted that focusing on different aspects, various researchers around the globe have used their own methodology in analysis. To Lee (2011, p. 149), in the past two decades, the research literature assessing gender role portrayal in school textbooks has continued to be markedly heterogeneous and has failed to achieve any noticeable imp rovement.

While some studies (Graci, 1989; Gupta and Lee, 1990; Hunter and Chick, 2005; Lee and Collins, 2008; Leskin, 2001; have concentrated on quantifiable features for analysis - the number of female and male characters is a common feature of analysis, others (e.g., Johansson \& Malms jo, 2009; Poulou, 1997; Stockdale, 2006) have examined less quantifiable features, such as the extent to which male or female characters are primarily responsible for "requesting", "seeking information", and "giving directives", Leskin (1998) applies 'systemic function grammar in analy zing EFL textbooks. Thomson and Otsuji (2003) examined business Japanese textbooks from both macro (social practices) and micro (linguistic discourses) level perspectives, using critical discourse analysis as the framework of their study. Another development in methods of gender analysis in school textbooks is computer concordancing (e.g., Carrol and Kowitz, 1994). Lee (2011) concluded that if individual res earchers continue to use their own research methods, it will be difficult to make a scientific comparis on of studies across different disciplines; thus the call for a standardized evaluative instrument in the concerted effort to co mbat sexism.

However, it is noted here that this call for a standardised method would have been inevitable if the goal were to propose gender in language learning universals as we have in other branches of linguistics e.g., language universals, gender and language universals. However, where the objective is to spotlight the undesirability of gender insensitiveness in learning materials and classroom interactions and call for revision, the empirical nature of every investigation and its data should determine the method. A new researcher might prefer the method used by earlier researchers just as Schmitz's (1975) proposed four categories for detecting sexis m exclusion (proportion of content about males and females); subordination (roles or occupations assigned to wo men); distortion (reinforcement of gender stereotypes); and degradation (condescending statements or generalizations about women) have been used by other researchers.

The difficulties that Graci (1989) (reported in Lee, 2011) encountered in the comparative study of 20 studie s of foreign language textbooks from 1975 and 1984 might be difficult to generalise to all the other studies that have been done till date. Time-frame, funding, research tools and other materials available to a researcher or group of researchers, the expertise of the researcher and the choice of data to work with might determine methodology. Thus it might be difficult to place a bar on methods or impose a particular method on researchers as doing so would be counterproductive. Perhaps, we should consider heterogeneity of methods as a healthy scholarship phenomenon. Therefore, Brugeilles and Cromer's (2009) contributions to textbook gender analysis should be welcomed and adapted just as any other method that is systematic should be recommended for use by other researchers. In fact, Brugeilles and Cromer's (2009) method addresses one aspect of textbooks - character "a new approach to capturing social representation through the character". This involves detailed examination of characterisation techniques in text passages and dialogues. In addition, with such undertaking, I would suggest other areas of social representation in sentence structures by looking at elements of transitivity, collocation, discourse patterns, image representation among others.

\section{AREAS FOR FURT HER STUDIES}

In her recommendations, Blu merg (2007) suggested that after decades, it is time to move beyond studies that describe gender bias in textbooks to research that evaluates the level and type of impact of such bias on female - and males. She 
added that the place to start this gender sensitization is during teacher training... therefore it is recommended that wherever teacher training includes some form of practice teaching, exercises of the sort designed in such profusion by Kalia (1986) be incorporated into their training.

Coming to developing countries (Africa), it is on record that the World Bank between 1990-2005 funded educational sector initiatives with specific gender components or an exclusively female clientele (Tembon, 2007). The programme targeted (i) provision of infrastructure to increase educational access (constructing rehabilitating schools and classrooms, building separate latrines for girls and boys) and (ii) learning interventions (increasing the numbers of female teachers, curriculum and textbooks reform, provision of textbooks and other educational materials and gender sensitization of personnel. The programme covered Nepal, Bangladesh, Chad, Gu inea and Ghana. These educational initiatives were claimed to have had explicit components or activities aimed at eliminating gender bias from curricu la and or textbooks.

Aside from the above co-ordinated programmes, it appears that very little has been done in this area in Africa, (barring Ansary and Babaii, 2009; Lamidi, 2009; Madu and Kasanga, 2005; McKinney, 2005; Tembo, 1984; Touorouzou, 2006; Page and Jha, 2009; the British Council, 2012).

The UBE scheme, in consonance with UNESCO gender equality goals, has amongst its goals equal accessibility to quality education by the year 2015. Although it is driving towards achieving numerical gender balance (bridging the gap between boys and girls enrolment), it appears that the stakeholders are oblivious of the other aspect of gender equality in education (quality not just quantity in education). In her recommendations, Blumerg (2007) stated that as countries succeed in achieving gender parity in enrolment, i.e., succeed at access, they should be encouraged to tackle and monitor and evaluate - "second level" problems, such as gender bias in textbooks and curricula. It is at this second level that studies in Sub-Sahara, the far East and other countries where little or no work has been done in this area are needed before moving on to talk studies. And since reductions in the intensity of gender bias in textbooks is considered as a useful indicator of gender equity in society (Blumerg, 2007), it is anticipated findings would not only create awareness but lead to plan of actions that will facilitate implementation (of the actions) of producing progressive textbooks by authors and publishers with the support of government agents who are to monitor and enforce the implementation.

In addition to these gaps that are to be filled, there are other gaps that subsequent studies might find interesting. Amongst them are collecting data from actors and stakeholders in the educational process. This includes teachers, learners, guardians and parents, government representatives and non-governmental organisations and authors and publishers of textbooks. For example, the uptakes of learners about their texts - the contents and how these contents affect/influence them in terms of their gender identity, gender roles are part of the areas to be considered in the research. Learners should be brought into focus groups to discuss their texts in relation to themselves and their society. Similarly, teachers' views about gender representations in texts that they select for teaching in the classroom should also be incorporated into future research. The usefulness of guidelines for teachers (teacher handbooks) that accompany texts for children should be brought to focus - they should be scrutinised for the inclusion/exclusion of gender issues.

It won't be out of place to harness parents/guardians' views about gender issues in the texts that are being used to teach their children just as the printed materials used by religious bodies for teaching children/youth classes in their meetings might be another source of data for investigation. Govern ment represen tatives and NGOs who are involved in the education process including trainers of teachers are not to be left out in discussing gender issues in learning materials selected for use in the classroom just as authors and publishers' uptake on these issues might be topics worth investigating.

Where preliminary studies of texts have reached a measurable stage with attendant results of the production of progressive texts (gender-fair textbooks) studies on talk around the text in the classroom between teachers and learners should naturally follow. And where the latter has been done, further studies on teachers' compliance might be necessary in order to ensure that no stone is left unturned in achieving gender equality in and through education.

Method-wise, it might be very difficult to be prescriptive. Textbooks contain many language and communicative tools - pictures, characterization, language structures, vocabulary development, speech production exercise and others. Researchers' chosen aspects of the text, their objectives among others should determine the method of analysis.

\section{CONCLUSION}

It is interesting to note that the concern about gender in language education studies (in learning materials and environment) that started not many years ago has grown so large and results of the undertakings have not only impacted on the educational sector but also on society at large with the attendant outcome of empowering women for national development in some countries. Government bodies and international organizations and non-governmental organizations recognize the contributions these studies make and have been funding research in the area with follow -up actions that have made tangible contributions to development. Since most studies are scattered in jo urnals, monographs and websites, a handy textbook of collection of materials/studies from various countries might be a welco me idea in the near future. Gender in learning materials should continue in under-researched sites just as studies on talk around the text should follow text studies. However, the impact of sexist and progressive texts should also be examined together with the uptakes of stakeholders on text and talks. Bar-placing on methods (data collection and analysis) might not be necessary if we are to promote flexibility that will create the atmosphere for robust research. 


\section{ACKNOWLEDGEMENT}

The paper is a product of a research on gender representation in learning materials in Nigeria funded by the British Academy under its 2011 Vis iting Scholar Sche me. I thank Professor Sara Mills (Sheffield Hallam University) for her comments on an earlier version of this paper.

\section{REFERENCES}

[1] Alderson, C. (1997). Models of language: whose? what for? what use? In A. Ryan \& A.Wray (eds.), Evolving models of language: British Studies in Applied Linguistics 12. Clevedon: BAAL/Multilingual Matters.

[2] Ansari, H. \& A. Babaii, (2003). On the manifestation of subliminal sexism in current Iranian secondary school ELT textbooks. Iranian Journal of Applied Linguistics 6, 57-69.

[3] Bailey, B. \& L. Parkes (1995). Gender: The Not so hidden issue in language arts materials used in Jamaica. Journal of Caribbean Studies 17.2, 265-278.

[4] Birjandi, P. \& S. Anabi (2006). English for the pre-university students. Tehran: Centre for the Publication of Iranian Textbooks.

[5] Blumerg, R. L. (2007). Gender bias in textbooks: A hidden obstacle on the road to gender equality in education. Paris: UNESCO. Back ground paper for 2008 Education for All Global Monitoring Report, Education for All by 2012 - Will we make it? www.unesdoc.unesco.org/images/0001500155509e.pdf. (14/08/2010).

[6] Brugeilles, C. \& S. Cromer (2009). Analysing gender representations in school textbooks. Paris: Universite Paris Ouest Nanterre Centre de Recherche Populations et Societetes (CERPOS).

[7] Byrd, P. 2001. Textbooks: Evaluation for selection and analysis for implementation. In M. Celce-Murcia (ed.), Teaching English as a second or foreign language. Boston: Heinle \& Heinle, 415-424.

[8] Cameron, D. (1998). The feminist critique of language. London: Routled ge.

[9] Carlson, M. (2007). Images and values in textbook and practice: Lan guage courses for immigrants in Sweden. In M. Carlson, et al. (eds.), Education in multicultural societies - Turkish and Swedish perspectives. Istanbul: Swedish Research Institute in Istanbul. 125-142.

[10] Carrol, D. \& J. Kowitz. (1994). Using concordancing techniques. In J. Sunderland, (ed.), Exploring gender. London: Prentice Hall. 73-82

[11] Cerezal, F. (1991). Gender discrimination and ELT textbooks. Paper presented at $25^{\text {th }}$ ATEFL Conference, Exeter.

[12] Cereal, F. (1994). Len guaje y discriminacion generica en libros de texto de ingles. Miscelanea 10.

[13] Chandran, S. K. \& M. H. Abdullah (2003). Gender bias in Malaysian English language textbooks. In J. Mukundan (ed.), Readings on ELT material. Serdang: Universiti Putra Malaysia Press.

[14] Child, I., Potter, E. H. \& E. M. Levine (1960). Children's textbooks and personality development: An exploration in the social psychology of education. In J. F. Rosenblith, J. F. \& A. Wesley (eds.). Causes of behaviour: Readings in child development and education psychology. Rockleigh, New Jersey: Allyn.

[15] Cincotta, M.S. (1978). Textbooks and their influences on sex-roles stereotypes formation. BABEL: Journal of the Australian Federation of MLTS Associations 14.3, 24-29.

[16] Davis, K. A. \& Skilton-Sylvester, E. (2004). Looking back, taking stock, moving forward: Investigating gender in TESOL. TESOL Quarterly 38.3, 381-404.

[17] Drayton, K. (1997). White men's knowledge: Sex, race and class in Caribbean English Language textbooks. In E. A. LeoRhy nie, B. Bailey \& C. Barrow (eds.), Gender: A multidisciplinary perspective. Kingston, Jamaica: Ian Randle Publishers.

[18] Foshay, E. M. (1990). Art in the bloom. London: Universe Publishers.

[19] Freire, P. (1970). Pedagogy of the oppressed. New York: Herder \& Herder.

[20] Gharbavi, A. \& S. A. Mousavi. (2012). A content analy sis of textbooks: Investigating gender bias as a social prominence in Iranian High School English textbooks. English Linguistics Research 1.1, 42-49.

[21] Gonzalez, M. (1990). El sexismo en la educacion: la discriminacion cotidiana. Ciudad Universitaria Rodrigo Facio: Editorial de la Universidad de Costa Rica.

[22] Graci, J. P. (1989). Are foreign language textbooks sexist? Exploration of models of evaluation. Foreign Language Annals 22, 77-86. http://dx.doi.org/10.1111/j.1944-9720.1989.tb02771.x (accessed 20/8/2010).

[23] Gupta, F. A. \& S. Y. A. Lee. (1990). Gender representation in English language textbooks used in Singapore primary schools. Language Education 4.1, 29-50.

[24] Hamdan, S. (2010). En glish-language textbooks reflect gender bias: A case study in Jordan. Advances in Gender and Education 2, 22-26.

[25] Hartman, J. \& E. L. Judd. (1978). Sexism and TESOL materials. TESOL Quarterly 12, 383-393.

[26] Healy, D. (2009). The representation of women and men in a modern EFL textbook: Are popular textbooks gender biased? Memoirs of the Osaka Institute of Technology, Series B 54.2, 91-100.

[27] Hellinger, M. (1980). "For men must work, and women must weep": Sexism in English Language textbooks used in German schools. Women's Studies International Quarterly 3, 267-275.

[28] Holmes, J. (1991). Lan guage and gender: a state-of-the-art survey article. Language Teaching 24.4, 207-20.

[29] Holmes, J. (2009). Gender and every day life: The new sociology. Oxon: Routledge, 10-14.

[30] Hsu, F. H. (1992). A case study of discriminatory gender stereotyping in Taiwan's elementary school textbooks. (Unpublished EdD Thesis). New York: Columbia University Teachers College.

[31] Jafri, R. (1993). Gender bias and female education in Pakistan. Lahore: Aurat Foundantion.

[32] Jaworski, A. (1983). Sexism in textbooks. British Journal of Language Teaching 21.2, 109-113.

[33] Johansson, S. \& K. Malmsjo. (2009). Gender bias in EFL textbook dialogues. Malmo hogskola.

[34] Jones, M., Kiteku, C. \& Sunderland, J. (1997). Discourse roles, gender and lan guage textbook dialogues: who learn what from John and Sally? Gender and Education 9.4, 469-490. 
[35] Jones, M., Kiteku, C. \& J. Sunderland. (1995). Discourse roles, gender and language textbook dialogues: Who learns what from John and Sally? Gender and Education 9.4, 469-490.

[36] Kalia, N. N. (1986). From sexism to equality: A handbook on how to eliminate sexist bias from our textbooks and other writings. New Delhi: New India Publications.

[37] Kanemaru, F. (1998). Sexism and Japanese English textbooks. The Language Teacher 22.5

[38] Khurshid, K., I. G. Gillani \& M. A. Hashmi. (2010). A study of the representation of female image in the textbooks of English and Urdu at secondary school level. Pakistan Journal of Social Sciences 30.2, 425-437.

[39] Lamidi, T. (2009). Gender-neutral pronoun usage among selected second language users of English in Nigeria. In Odebunmi, A., E. A. Arua \& S. Arimi (eds.) Language, politics and gender: A festschrift in honour of Professor Y. K. Yusuf. Ibadan: Centre for Black African Art and Civilization (CBAAC). 191-211.

[40] Lee, J. F. K. (2007). Acceptability of sexist language among young people in Hong Kong. Sex Roles 56, 285-295.

[41] Lee, J. F. K. (2011). Gender representation - An exploration of standardized evaluation methods (Book Review) Sex Roles 64, 148-150.

[42] Lee, J. F. K. \& Collin, P. (2008). Gender Voices in Hong Kong English Textbooks - Some Past and Current Practices. Sex Roles 59, 127-137.

[43] Lesikin, I. (2001). Determining social prominence. A methodology for uncovering gender bias in ESL textbooks. In D. R. Hall \& A. Hewing, A. (eds.) Innovation in Eng lish language teaching. London: Routledge. 275-282.

[44] Madu, B. N. \& L. A. Kasanga (2005). Sex differences in the acquisition of English as a second language. Gender and Behaviour 3, 442-452.

[45] McCormick, T. M. (1994). Creating the non-sexist classroom - A multicultural approach. New York: Teachers College Press.

[46] McCormick, P. (1995). Are girls taught to fail? U.S. Catholic 60.2, 38-42.

[47] McKinney, C. (2005). Textbooks for Diverse Learners: A critical analy sis of learning materials used in South African Schools. Cape Town: HRSC.2005.

[48] Mills, S. (1995). Feminist sty listics. London: Routledge.

[49] Mukundan, J. \& V. Nimehchisalem. (2008). Gender representation in Malaysian Secondary School English Language textbooks. Indonesian Journal of English Language Teaching 4.2, 155-173.

[50] Mustedanagic, A. (2010). Gender in English language and EFL textbooks. A term paper submitted to Halmstad University. Hogskola

[51] Mukundan, J. (2003). A composite framework for ESL textbook evaluation. In J. Mukundan (Ed.), Readings on ELT material. Serdang: Universiti Putra Malaysia Press.

[52] Page, E. \& J. Jha. (2009). Exploring gender and stereotyping in secondary schools. London: The Commonwealth Secretariat.

[53] Porecca, K. L. (1984). Sexism in current ESL textbooks. TESOL Quarterly 18.4, 705-724.

[54] Poulou, S. (1997). Sexism in the discourse roles of textbook dialogues. Language Learning Journal 15, 68-73.

[55] Renner, C. E. (1997). Women are 'busy, tall and beautiful': Looking at sexism in EFL materials. Paper presented at the National Seminar: Mind the Language (Rome, 1996) and at the Annual Meeting of TESOL, Orlando.

[56] Robson, D. (2001). Women and minorities in economics textbooks: Are they being adequately represented? The Journal of Economic Education 32.2, 186-191.

[57] Rogers, C. (1980). A way of being. Boston: Houghton Mifflin.

[58] Ross, H. \& Shi, J. (2003). Entering the gendered world of teaching materis, Part II. Chinese Education and Society 36.3, 3-9.

[59] Sadker, M. \& D. Sadker. (1980). Sexism in teacher education texts. Harvard Educational Review 50, 36-46.

[60] Sadker, D. (2002). An educator's primer to the gender war. Phi Delta Kappan 84 .3, 235-44.

[61] Sabir, A. (2008). Review of Moroccan school textbooks for gender equality and human rights by Regional Director (HREA): Project Results. http://www.achr.hn/newen63.html, 1-2. (accessed 8/7/2012).

[62] Sano, F., M. Ida \& T. Hardy. (2001). Gender representations in Japanese EFL textbooks. JALT 2001 Conference Proceedings.

[63] Schmitz, B. (1975). Sexism in French language textbooks. In R. Lafay ette (ed.) The Cultural revolution in foreign language teaching. Skokie, III.: National Textbook Co. 119-130.

[64] Seng, T. C. (2003). Gender: The missing factor in the selection of materials. In J. Mukundan (ed.), Readings on ELT Material. Serdang: Universiti Putra Malaysia Press.

[65] Song, H. (2003). Who is a good student? An exploration and analy sis of stereotyped gender impressions among junior middle school teachers of science subjects. Chinese Education and Society 36.3, 43-54.

[66] Skelton, C. (1997). Revisiting gender issues in reading schemes. Education 3-13, 25.1, 37-43.

[67] SIDA, (2007). Progress in educational development: SIDA's contributions, 2006. Stockholm: Swedish International Development Agency.

[68] Sileo, T. W., \& M. Prater. (1998). Preparing professionals for partnerships with parents of students with disabilities: Textbook considerations regarding cultural diversity. Exception Children 64.4, 513-28.

[69] Spender, D. (1992). Invisible women: The schooling scandal. London: The Women Press.

[70] Stockdale, D.A. (2006). Gender representation in an EFL textbook. A paper submitted to the School of Humanities of the University of Birmingham, UK.

[71] Stromquist, N., M. Lee \& B. Brock-Utne. (1998). The explicit and the hidden school, In N. Stromquist \& K. Monkman (eds.), Women in the third world: An encyclopedia of contemporary issues. New York: Garland Publishing, Inc. 397-407.

[72] Sunderland, J. (1994). Introduction. In J. Sunderland (ed.), Exploring gender: Questions and implications for English language education. London: Prentice Hall.

[73] Sunderland, J. (2000). Issues of gender representations in textbooks: A state of the art studies. Language Teaching 33.4, 203223.

[74] Sunderland, J., F. A. Rahim, M. Cowley, C. Leontzakou \& J. Shattuck. (2002). From representation towards dicursive practices: Gender in the foreign language textbook revisited. In L. Litosseliti \& J. Sunderland, (eds.), Gender identity and discourse analysis. Amsterdam: John Benjamins. 223-256. 
[75] Talansky, S. (1986). Sex role stereotyping in TEFL teaching materials. Perspectives 11.3, 32-41.

[76] Tembo, L. P. (1984). Men and women in school textbooks. Paris: UNESCO.

[77] Tembo, M. (2007). Personal interview. Washington DC, March 12.

[78] Thomson, C. K., \& Otsuji, E. (2003). Evaluation of business Japanese textbooks: Issues of gender. Japanese Studies 23, 185202.

[79] Treichler, P. \& F. Frank. (1989). Introduction: Scholarship, feminism, and lan guage change. In Frank, F. \& P. Treichler (eds.), Language gender and professional writing: Theoretical approaches and guidelines for non-sexist usage. NY: MLA. 1-32.

[80] U'ren, M. B. (1971). The image of woman in textbooks. In V. Gornick \& B. K. Moran (eds.) Woman in sexist society: Studies in power and powerlessness. New York: Basic Books.

[81] Westbury, I. (1990). Textbooks, textbook publishers, and the quality of schooling. In. D. L. Elliot \& A. Woodward (eds.), Textbooks and Schooling in the United States. Chicago, IL: University of Chicago Press. 1-22.

[82] Whiteley, P. (1996). The gender fairness of integrated science textbooks used in Jamaican High Schools. International Journal of Science Education 18.8, 969-976.

[83] Yaqin, L. 2002. Socialization of the gender role as seen from Bao Bao's family classroom. Chinese Education and Society 35, $14-22$.

[84] Yi, J. (2002). A discussion on the form of elementary school social teaching materials from the angle of gender analysis. Chinese Education and Society 35.5, 63-76.

[85] Zhang, Y. (2002). Analy sis of the social gender culture in children's games. Chinese Education and Society 35.5, 77-91.

[86] Zhang, L. (2003). A study of junior middle school language teaching gender issues. Chinese Education and Society 36.3, 19-26.

[87] Zhao, Y. (2002). Analy sis of the social gender culture in children's games. Chinese Education and Society 35.5, 77-91.

[88] Zhao, P. (2003). Mother and I: An analysis of the gender roles of two generations of females in junior middle school Englishlan guage teaching materials. Chinese Education and Society 36.3, 27-33.

[89] Zittleman, K. \& D. Sadker. (2002). Gender bias in teacher education texts: New (and old) lessons. Journal of Teacher Education 53.2, 168-181.

Abolaji S. Mustapha holds doctoral degree in sociolinguistics from the University of Essex, Colchester, UK and teaches in the Dept of English, Lagos State University, Nigeria. He is currently at Sheffield Hallam University, Sheffield, as a British Academy Visiting Scholar. He has about forty publications in local and international academic journals and chapters in books. His recent book Gender in Language Use was published in 2011. 